\title{
Genetic analysis of SLC47A1, SLC22A1, SLC22A2, ATM gene polymorphisms among diabetics in an Indian population
}

\author{
Sagar D. Phate ${ }^{1}$, Bharti R. Daswani2*, Deepika N. Mishra ${ }^{2}$, Kedar S. Joshi ${ }^{3}$
}

\begin{abstract}
${ }^{1}$ Department of Pharmacology, Government Medical College, Akola, Maharashtra, India
${ }^{2}$ Department of Pharmacology, B.J. Government Medical College and Sassoon General Hospital, Pune, Maharashtra, India

${ }^{3}$ Genesupport Lab (Advisor), Pune, Maharashtra India
\end{abstract}

Received: 05 April 2020

Revised: 10 May 2020

Accepted: 11 May 2020

\section{*Correspondence:}

Dr. Bharti R. Daswani,

Email: sagarphate@gmail.com

Copyright: ( $)$ the author(s), publisher and licensee Medip Academy. This is an open-access article distributed under the terms of the Creative Commons Attribution Non-Commercial License, which permits unrestricted non-commercial use, distribution, and reproduction in any medium, provided the original work is properly cited.

\begin{abstract}
Background: Metformin is a first-line therapy for type 2 diabetes mellitus. However, the glycaemic response to metformin is likely to be affected by polymorphisms of transporter genes. Therefore, the study was done with the aim to assess demographic distribution of transporter genotypes involved in disposition and action of metformin.

Methods: This cross-sectional, observational, single centre, clinical study was conducted in 80 diabetic patients recruited from medicine OPD. Descriptive analysis was done for distribution of the four transporter genotypes viz. SLC47A1 (rs2289669), ATM (rs11212617), SLC22A2 (rs316019) and SLC22A1 (rs622342). Genotyping was determined by DNA extraction, agarose gel electrophoresis, estimation of DNA concentration, polymerase chain reaction, DNA sequencing, sequencing analysis.

Results: Transporter genotype analysis showed that for SLC47A1 (rs2289669) transporter, 31.25\% and 26.25\% were homozygous for AA and GG allele respectively, while 42.5\% were heterozygous (AG). For ATM (rs11212617), SLC22A2 (rs316019) and SLC22A1 (rs622342) transporter, 45\% and 10\%, $1.25 \%$ and 80\%, 58.75\% and $7.50 \%$ were homozygous for AA and CC allele respectively; while 45\%, 18.75\%, 33.75\% were heterozygous (AC) respectively. Interethnic differences in the genotype and allele frequencies of SLC22A1 (rs622342) and ATM (rs11212617) gene polymorphism were observed when compared with other major populations.

Conclusions: In the genotypic distribution of four transporter genotype study showed that there was an ethnic variation in allelic distribution of allele A and C of ATM (rs11212617) and SLC22A1 (rs622342) while AA genotype of SLC22A2 (rs316019) was rare genotype and allele 'A' was major allele found in our study. The study data observed would justify further pharmacogenetic studies to evaluate the role of gene polymorphism in the therapeutic efficacy of metformin.
\end{abstract}

Keywords: Diabetes, Metformin, Transporter gene, Polymorphism

\section{INTRODUCTION}

The most commonly prescribed anti diabetic drug worldwide is metformin and it is use as a first-line therapy for type 2 diabetes mellitus. ${ }^{1}$ Although, metformin is very well tolerated by most of the diabetic patients, but glycaemic control to metformin considerably varies among the patients. Some patients showed significant response, whereas others are benefited to lesser extent/not at all. ${ }^{2}$ Studies have shown that metformin monotherapy is not effective in $\sim 30 \%$ patients and $20-60 \%$ users shows common side-effects, which 
marginally showing non-compliance up to $30 \%$ of users and discontinuation of treatment in $5-10 \%$ of all cases. The most important factors that influence the effectiveness and response to metformin, apart from severity of hyperglycaemia, are the SLC22A1 and C11ORF65 genes. The efficacy of metformin is primarily affected by polymorphisms in these two genes. ${ }^{3}$

The SLC22A1 gene encodes the trans-membrane transporter1 (OCT1) important for the transport of metformin to the cells and outside of the cells, while the other polymorphism is located in the C11ORF65 gene. This gene regulates the activity of the ATM gene, which is responsible for the phosphorylation and the activation of the AMPK enzyme. ${ }^{4}$

The pharmacokinetics of metformin is affected by polymorphism in SLC22A2 gene. ${ }^{5}$ This gene encodes Polyspecific organic cation transporters in the intestine, kidney, liver, and other organs. These transporters are also involved in elimination of many endogenous small organic cations, drugs and environmental toxins.

Metformin is not metabolized in the liver or kidney but rather excreted intact in the urine. The transport of Metformin has been recently reviewed by Gong, Goswami et al. $^{6}$ Several transporters, for which Metformin is a likely substrate, have been identified e.g. organic cation transporter (OCT) 1-3, plasma membrane monoamine transporter (PMAT), multidrug and toxin extrusion protein (MATE) 1-2, serotonin transporter (SERT) and high-affinity choline transporter (CHT), ${ }^{7,8}$ OCTs are members of solute carrier family 22 (SLC22), encoded on chromosome 6q26. OCTs are expressed in several tissues, including the intestine, liver, kidney, brain, muscle and heart. ${ }^{7}$ OCT1 is predominantly expressed in the liver, but plays an important role in the transfer of cations, including Metformin, from the gut lumen to the interstitium. Initial studies report localised OCT1 to the basolateral membrane, more recent studies found that OCT1 on the apical surface of intestinal epithelial cells. OCT2 is expressed mainly in the kidney and is partly responsible for the renal excretion of Metformin. OCT3 is mainly expressed in the skeletal muscle but is also expressed in the intestine. ${ }^{9}$

Plasma monoamine transporter (SLC29A4) and organic cation transporter 3 (SLC22A3) are responsible for metformin uptake from the intestine, then metformin is transported into the bloodstream by OCT1 (SLC22A1) and finally other members of the OCT family are responsible for target tissues uptake. Multi-antimicrobial extrusion protein 1 (MATE1) which is encoded by SLC47A1 gene removed metformin actively from target tissues and metformin is excreted from proximal tubule cells into the urine by MATE1 and MATE2 (SLC47A2) About $50 \%$ of an orally administered dose is absorbed into the systemic circulation. The half-life of the drug measured in plasma is between 4 and $8 \mathrm{~h}$ in individuals without renal dysfunction, and the clearance exceeds glomerular filtration rate, consistent with tubular secretion. $^{10}$

PMAT was originally identified as a monoamine transporter from the equilibrative nucleoside transporter (ENT) family, found predominantly in the brain and central nervous system. However latter studies found PMAT in many tissues throughout the body and it transports metformin from the intestine with similar affinity to the OCTs. Now, it was found that PMAT located at the tips of the mucosal epithelial layer and involved in metformin uptake. ${ }^{11}$

Genetic variabilities of metformin transporters in the gut, liver and kidney have been shown to affect the pharmacokinetics and thus indirectly affecting the efficacy of metformin in T2D patients. ${ }^{12}$

Thus, metformin shows pharmacokinetic as well as pharmacodynamics variations by virtue of the genetic variations in transporters. Therefore, it is apparently essential to study the distribution of the genotypes of the various transporters involved disposition and action of metformin, which may then help in predicting the responsiveness to metformin. Though there is western literature on distribution of genotype, there is no such data on the Indian population.

The objectives of our study were to analyse and compare the demographic distribution of four transporter genotypes SLC47A1, SLC22A1, ATM and SLC22A2 involved in disposition and action of metformin in Indian population.

\section{METHODS}

This study was a prospective, observational, single centre, clinical study. The study was conducted in a tertiary care hospital where patients attending the medicine outpatient department (OPD)/diabetes clinic were recruited for the study. The study period was from January 2017 to December 2018. A synopsis of the study protocol was submitted to the Institutional Ethics Committee and approval was obtained. 80 subjects were recruited for genotype analysis.

\section{Patient inclusion criteria}

Newly diagnosed cases (male/female) of diabetes mellitus type 2 (fasting plasma glucose $>126 \mathrm{mg} \%$ or 2 hours postprandial plasma glucose $>200 \mathrm{mg} \%$ ); and HbA1c $\geq 6.8 \%$ included in the study, who, as per the clinician, are deemed fit to receive metformin monotherapy.

\section{Exclusion criteria}

Exclusion criteria were age less than 18 years or more than 60 years of age and type 1 diabetes mellitus. 


\section{Estimation of genotype}

$5 \mathrm{ml}$ of EDTA blood was collected from study patients and was stored at $4-8^{\circ} \mathrm{c}$. Then EDTA blood was transported to the Genesupport laboratory.

DNA extraction was done by using DN easy blood and tissue DNA kit (Qiagen, Germany). Gel photograph was recorded using gel Doc-XR gel documentation system the Qubit@ (previously known as Quant-I T TM) dsDNA BR assay kit which is designed specifically for use with the Qubit ${ }^{\circledR}$ fluorometer was used to quantify DNA concentration. Polymerase chain reaction (PCR) of the human DNA was performed using primers specific for each mutation locus. The purified PCR product was then checked by gel electrophoresis and then used for DNA sequencing. Sequencing of the purified PCR product ( $200 \mathrm{ng} / \mathrm{reaction}$ ) was carried out using $1.6 \mathrm{p} / \mathrm{moles}$ of a sequencing primer and applied biosystems big dye terminator v3.1 cycle sequencing kit in a total volume of $10 \mu \mathrm{l}$. The sequence data was retrieved in FASTA format and QC checked using quality value bars. The chromas pro v3.1 software was used for sequence assemble. Sequence alignment of reference and samples was done using clustalw online sequence alignment tool (http://www.genome.jp/tools/clustalw/) (Figures 1-4). ${ }^{13-16}$

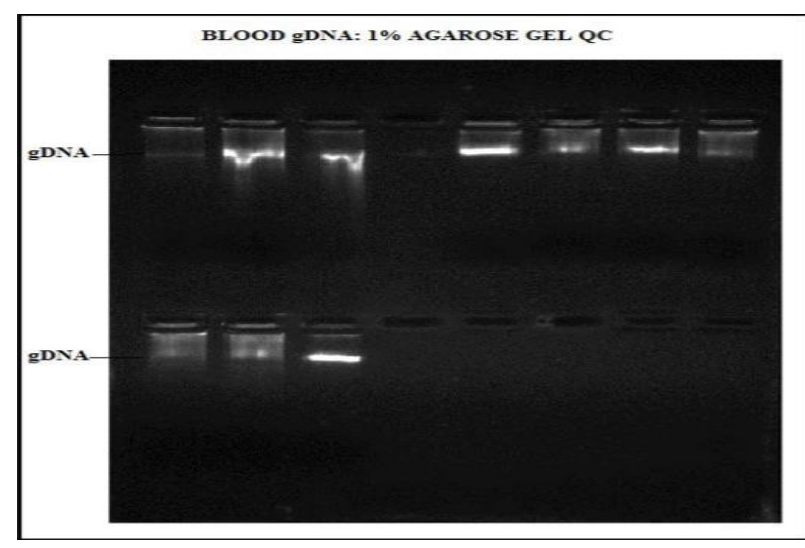

Figure 1: Blood gDNA extraction from blood samples, $5 \mu \mathrm{l}$ gDNA loaded on $1 \%$ agarose gel.

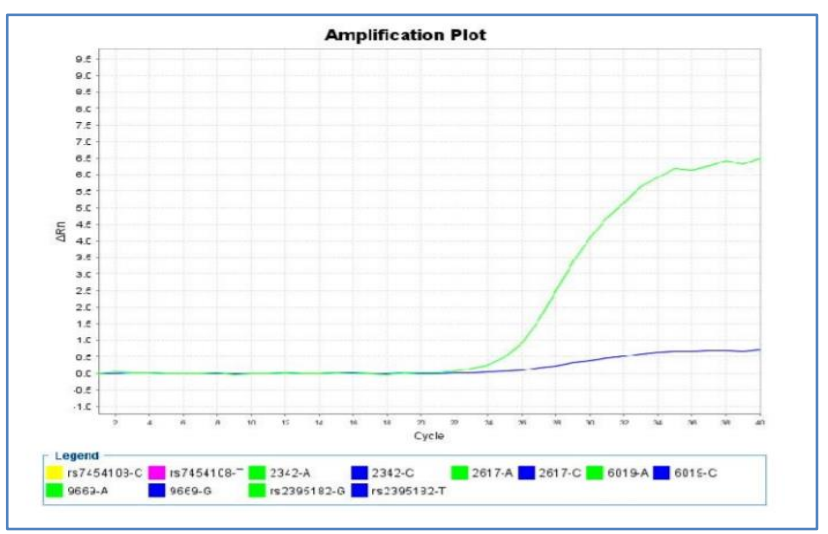

Figure 2: AA genotype (green colour amplification) of the sample.

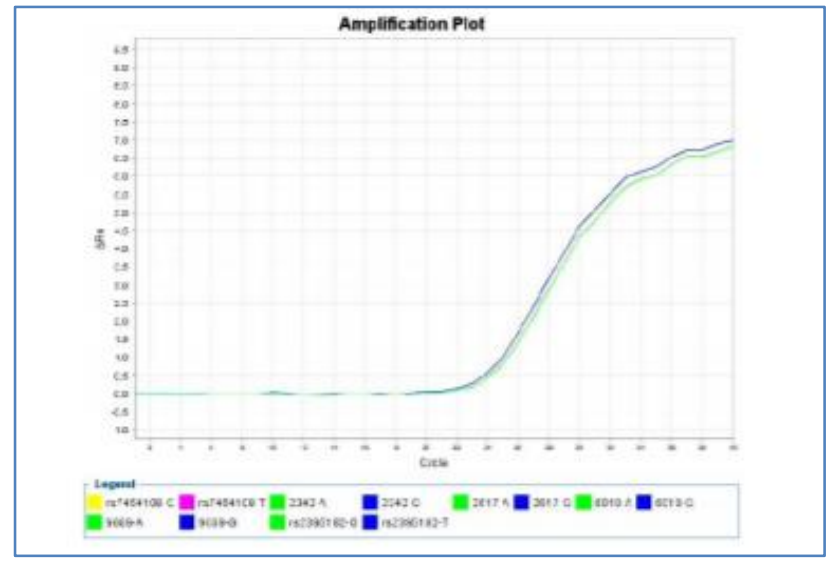

Figure 3: AG genotype (green/blue colour amplifications) of the sample.

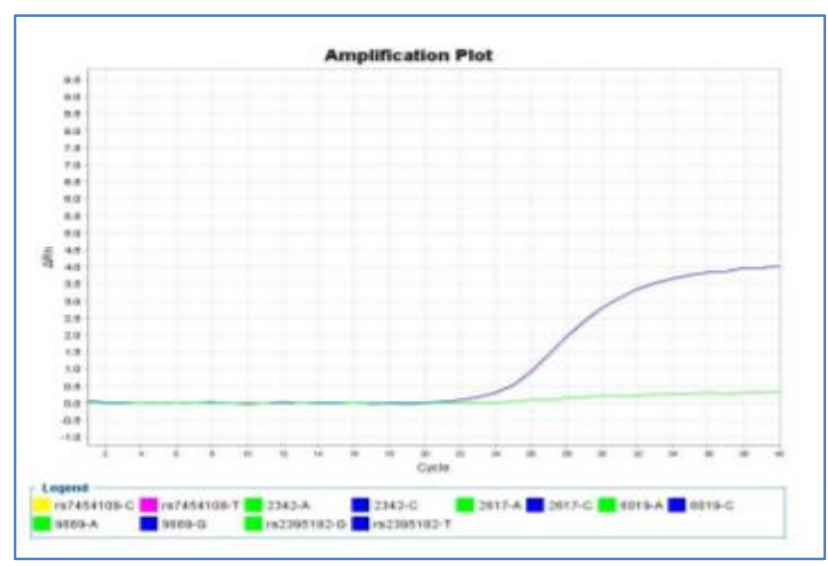

Figure 4: GG genotype (blue colour amplification) of the sample.

\section{Statistical analysis}

Descriptive analysis was performed for distribution of each of the 4 transporter genotypes. The direct gene counting method was used to determine the frequency of genotypes and alleles (Table 1).

Table 1: Gene transporter and single nucleotide polymorphism included in statistical analysis.

\begin{tabular}{|lll|}
\hline Gene & SNP & Patient genotype \\
\hline SLC47A1 & rs2289669 & AA/AG/GG \\
\hline SLC22A1 & rs622342 & AA/AC/CC \\
\hline ATM & rs11212617 & AA/AC/CC \\
\hline SLC22A2 & rs316019 & AA/AC/CC \\
\hline
\end{tabular}

SNP- single nucleotide polymorphism.

\section{RESULTS}

To study the distribution of transporter genotypes, a total of 80 subjects were enrolled in this study. Out of 80 patients $51(63.75 \%)$ were males and $29(36.25 \%)$ were females. None of the baseline characteristics showed 
statistically significant difference and were comparable in both the groups (Table 2).

Table 3, illustrates the genotype frequencies of four gene transporter obtained in the study population. Among 80 patients' that had been enrolled and seen for SLC47A1 (rs2289669) transporter genotypes, $42.5 \%$ were found to be heterozygous allele (AG). AG was the predominant genotype in case of SLC47A1 (rs2289669) gene transporter. CC genotype (10\%) was the less frequently observed genotype as compared to other genotype in case of ATM (rs11212617) gene transporter. AA genotype $(1.25 \%)$ was the rare while CC genotype $(80 \%)$ was the predominant genotype found in case of SLC22A2 (rs316019) gene transporter. While in case of SLC22A1 (rs622342), CC genotype was the infrequent genotype.

Table 2: Baseline characteristics of the patients $(\mathbf{n}=\mathbf{8 0})$.

\begin{tabular}{|lll|}
\hline Variables & $\begin{array}{l}\text { Males }(\mathbf{n = 5 1}) \\
\text { Range (mean } \\
\pm \text { SD) }\end{array}$ & $\begin{array}{l}\text { Females }(\mathbf{n = 2 9}) \\
\text { Range (mean } \\
\mathbf{\pm S D})\end{array}$ \\
\hline $\begin{array}{l}\text { Age } \\
\text { (years) }\end{array}$ & $\begin{array}{l}24-60 \\
(45.80 \pm 8.86)\end{array}$ & $\begin{array}{l}32-58 \\
(44.172 \pm 7.474)\end{array}$ \\
\hline $\begin{array}{l}\text { Weight } \\
\text { (kg) }\end{array}$ & $51-89$ & $49-85$ \\
\hline $\begin{array}{l}\text { Height } \\
\text { (cm) }\end{array}$ & $148.76 \pm 9.82)$ & $(68.13 \pm 10.48)$ \\
\hline
\end{tabular}

Table 4, illustrates the comparisons among four transporter gene allele frequencies in worldwide populations. In case of SLC47A1 (rs2289669) gene transporter there was no statistically significant difference seen in allele frequencies when compared between the Indian diabetic patients and Chinese T2DM patients $(\mathrm{p}>0.05)$.
While in case of ATM (rs11212617) there was a statistically significant difference seen among other ethnicities but similar result was seen in south Indian population.

Table 3: Frequency of transporter genotype among diabetes Indian population $(n=80)$.

\begin{tabular}{|c|c|c|}
\hline Gene (SNP) & Genotype & $\begin{array}{l}\text { Frequency of } \\
\text { transporter genotype } \\
(\%)\end{array}$ \\
\hline \multirow{3}{*}{$\begin{array}{l}\text { SLC47A1 } \\
(\mathrm{rs2289669)}\end{array}$} & AA & $25(31.25)$ \\
\hline & GG & $21(26.25)$ \\
\hline & $\mathrm{AG}$ & $34(42.5)$ \\
\hline \multirow{3}{*}{$\begin{array}{l}\text { ATM } \\
(\text { rs11212617) }\end{array}$} & $\mathrm{AA}$ & $36(45)$ \\
\hline & $\mathrm{CC}$ & $8(10)$ \\
\hline & $\mathrm{AC}$ & $36(45)$ \\
\hline \multirow{3}{*}{$\begin{array}{l}\text { SLC22A2 } \\
(\text { rs316019) }\end{array}$} & AA & $1(1.25)$ \\
\hline & $\mathrm{CC}$ & $64(80)$ \\
\hline & $\mathrm{AC}$ & $15(18.75)$ \\
\hline \multirow{3}{*}{$\begin{array}{l}\text { SLC22A1 } \\
\text { (rs622342) }\end{array}$} & AA & $47(58.75)$ \\
\hline & $\mathrm{CC}$ & $6(7.5)$ \\
\hline & $\mathrm{AC}$ & $27(33.75)$ \\
\hline
\end{tabular}

SNP- single nucleotide polymorphism.

Bangladeshi population showed the similar pattern of SLC22A2 (rs316019) genotypic distribution of homozygous allele $(79.2 \%)$ when compared to present study population $(81.25 \%)$. And finally, in the case of SLC22A1 (rs622342) similar frequency (A-75.6\%, C$24.4 \%$ ) of allele is seen when compared with Indian Tamilian population (A-75.5\%, C-24.5\%). But there was significant difference seen among other ethnicities such as Netherlands $(\mathrm{p}<0.05)$.

Table 4: Frequency of four transporter gene variants in different ethnicities as compared with the study population (Indian).

\begin{tabular}{|c|c|c|c|c|c|c|c|c|c|}
\hline \multirow{3}{*}{ Population } & \multirow{3}{*}{$\mathbf{N}$} & \multicolumn{8}{|c|}{ Allele frequency (\%) } \\
\hline & & \multicolumn{2}{|c|}{$\begin{array}{l}\text { SLC47A1 } \\
\text { (rs2289669) }\end{array}$} & \multicolumn{2}{|c|}{$\begin{array}{l}\text { ATM } \\
\text { (rs11212617) }\end{array}$} & \multicolumn{2}{|c|}{$\begin{array}{l}\text { SLC22A2 } \\
\text { (rs316019) }\end{array}$} & \multicolumn{2}{|c|}{$\begin{array}{l}\text { SLC22A1 } \\
\text { (rs622342) }\end{array}$} \\
\hline & & A $(\%)$ & G (\%) & A (\%) & $\mathrm{C}(\%)$ & A/G (\%) & $\mathrm{C} / \mathrm{T}(\%)$ & A $(\%)$ & $\mathrm{C}(\%)$ \\
\hline $\begin{array}{l}\text { Indian } \\
\text { population\# }\end{array}$ & 80 & 52.5 & 47.5 & 67.5 & 32.5 & 10.6 & 89.4 & 75.6 & 24.4 \\
\hline Indian Tamilian $^{13}$ & 112 & ND & ND & ND & ND & ND & ND & 75.5 & 24.5 \\
\hline Netherlands ${ }^{13}$ & 102 & ND & ND & ND & ND & ND & ND & 63 & $37 *$ \\
\hline $\begin{array}{l}\text { Chinese T2DM } \\
\text { patients }^{14}\end{array}$ & 267 & 52.81 & 47.19 & ND & ND & ND & ND & ND & ND \\
\hline Caucasians $^{15}$ & 113 & ND & ND & 53.3 & $46.5^{*}$ & ND & ND & ND & ND \\
\hline Chinese $^{15}$ & 43 & ND & ND & 31.4 & $68.6^{*}$ & ND & ND & ND & ND \\
\hline Japanese $^{15}$ & 86 & ND & ND & 38.4 & $61.6^{*}$ & ND & ND & ND & ND \\
\hline Africans ${ }^{15}$ & 113 & ND & ND & 18.6 & $81.4^{*}$ & ND & ND & ND & ND \\
\hline South Indians ${ }^{15}$ & 118 & ND & ND & 65.2 & 35.8 & ND & ND & ND & ND \\
\hline $\begin{array}{l}\text { Bangladeshi } \\
\text { population }^{16}\end{array}$ & 125 & ND & ND & ND & ND & 88.62 & 11.37 & ND & ND \\
\hline
\end{tabular}

\#Present study, ND- not determined, ${ }^{*} \mathrm{p}<0.05$ is considered statistically significant. 


\section{DISCUSSION}

Number of studies have shown that polymorphism in different transporters affect the metformin pharmacokinetics and indirectly the efficacy. The major transporters responsible for metformin transport across membrane and uptake in different tissues are OCT1, OCT2, MATE 1 and ATM. Hence, study was plan to study the genotypic distribution of transporters SLC22A1 rs622342 (OCT-1), ATM rs11212617, SLC22A2 rs316019 (OCT2) and SLC47A1 rs2289669 (MATE 1) which are associated with disposition of metformin in Indian diabetic population.

Among 80 patients' that had been enrolled and seen for SLC47A1 (rs2289669) transporter genotypes, 31.25\% and $26.25 \%$ were found to be homozygous for major allele (AA) and minor allele (GG) respectively; while $42.5 \%$ were found to be heterozygous allele (AG). AG was the predominant genotype in case of SLC47A1 (rs2289669) gene transporter. These results are similar in the study conducted by Xiao, Guo, and Li et al, where they found the 267 T2D patients in Chinese population, AA genotype were $28.84 \%$, GG genotype were $23.22 \%$ and $\mathrm{AG}$ genotype was predominant $47.94 \% .{ }^{17}$ So it is probable that there is no ethnic variation present for SLC47A1 (rs2289669) transporter gene among the different populations. But there is need further study to conclude this. Among 80 patients' that had been enrolled and seen for ATM (rs11212617) transporter genotypes, $45 \%$ and $10 \%$ were found to be homozygous for major allele (AA) and minor allele (CC) respectively; while $45 \%$ were found to be heterozygous allele (AC). CC genotype was the less frequently observed genotype as compared to other genotype in case of ATM (rs11212617) gene transporter. Similar results were found in the study conducted in south Indian population by Vilvanathan et al, where among 118 T2D patients $48.4 \%$ had heterozygous allele AC. The allelic distribution of ATM (rs11212617) was $67.5 \%$ for A allele and $32.5 \%$ for $\mathrm{C}$ allele, while the allelic distribution among different ethnicities reported were Caucasians $(\mathrm{A}=53.3 \%, \mathrm{C}=$ $46.5 \%)$, Chinese $(\mathrm{A}=31.4 \%, \mathrm{C}=68.6 \%)$, Japanese $(\mathrm{A}=$ $38.4 \%, \mathrm{C}=61.6 \%)$, and Africans $(\mathrm{A}=18.6 \%, \mathrm{C}=81.4 \%)$, this suggest that there is a wide variation seen in genotypic distribution of ATM (rs11212617) transporter gene. ${ }^{18}$ Then among 80 patients' that had been enrolled and seen for SLC22A2 (rs316019) transporter genotypes, $1.25 \%$ and $80 \%$ were found to be homozygous for allele (AA) and allele (CC) respectively; while $18.75 \%$ were found to be heterozygous allele (AC). AA genotype was the rare while $\mathrm{CC}$ genotype was the predominant genotype found in case of SLC22A2 (rs316019) gene transporter. In the study conducted on the Bangladeshi diabetic patients $(n=125), 79.62 \%$ had the homozygous allele GG. ${ }^{19}$ So it is probable that homozygous allele is the predominant allele in case of SLC22A2 (rs316019) transporter genotypes among other ethnicities.
And finally, among 80 patients' that had been enrolled and seen for SLC22A1 (rs622342) transporter genotypes, $58.75 \%$ and $7.50 \%$ were found to be homozygous for major allele (AA) and minor allele (CC) respectively; while $33.75 \%$ were found to be heterozygous allele (AC). AA genotype was the predominant genotype while; CC genotype was the infrequent genotype found in case of SLC22A1 gene transporter. Similar results were seen in the study conducted by Umamaheswaran et al, in Tamilian population $(\mathrm{n}=112)$, where $59 \%$ had AA genotype, $33 \%$ had AC genotype and $8 \%$ had CC genotype at SLC22A1 rs622342 gene variant. Thus, it is most likely that similar genotypic distributions for SLC22A1 rs622342 present among Indian population. ${ }^{20}$

\section{CONCLUSION}

We found that there was wide variation in genotypic distributions of SLC22A1 (rs622342) and ATM (rs11212617) among different ethnicities but there was no variation in genotypic distributions seen in different Indian population. For SLC47A1 (rs2289669) genotypic distributions no ethnic variation seen among the major population of world viz China and India. In SLC22A2 (rs316019) genotypic distributions, homozygous allele is the predominant allele.

\section{ACKNOWLEDGEMENTS}

The authors thank the study participants and Genesupport lab Banner Pune for their technical support.

Funding: No funding sources

Conflict of interest: None declared

Ethical approval: The study was approved by the Institutional Ethics Committee

\section{REFERENCES}

1. Scarpello JH, Howlett HC. Metformin therapy and clinical uses. Diab Vasc Dis Res. 2008;5:157-67.

2. Graham GG, Punt J, Arora M, Day RO, Doogue MP, Duong JK, et al. Clinical pharmacokinetics of metformin. Clin Pharmacokinet. 2011;50:81-98.

3. Muller J, Lips KS, Metzner L, Neubert RH, Koepsell $\mathrm{H}$, Brandsch $\mathrm{M}$. Drug specificity and intestinal membrane localization of human organic cation transporters (OCT). Biochem Pharmacol. 2005;70:1851-60.

4. Nies AT, Koepsell H, Winter S, Burk O, Klein K, Kerb R, et al. Expression of organic cation transporters OCT1 (SLC22A1) and OCT3 (SLC22A3) is affected by genetic factors and cholestasis in human liver. Hepatology. 2009;50:1227-40.

5. Chen Y, Li S, Brown C, Cheatham S, Castro RA, Leabman MK, et al. Effect of genetic variation in the organic cation transporter 2 on the renal elimination of metformin. Pharmacogenetics Genom. 2009; 19(7):497-504. 
6. Gong L, Goswami S, Giacomini KM, Altman RB, Klein TE. Metformin pathways: pharmacokinetics and pharmacodynamics. Pharmacogenet Genomics. 2012;22:820-7.

7. Shu Y, Sheardown SA, Brown C, Owen RP, Zhang $\mathrm{S}$, Castro RA, et al. Effect of genetic variation in the organic cation transporter 1 (OCT1) on metformin action. J Clin Invest. 2007;117:1422-31.

8. Tsuda M, Terada T, Ueba M, Sato T, Masuda S, Katsura $\mathrm{T}$, et al. Involvement of human multidrug and toxin extrusion 1 in the drug interaction between cimetidine and metformin in renal epithelial cells. $\mathrm{J}$ Pharmacol Exp Ther. 2009;329:185-91.

9. Sato T, Masuda S, Yonezawa A, Tanihara Y, Katsura T, Inui K. Transcellular transport of organic cations in double-transfected MDCK cells expressing human organic cation transporters hOCT1/hMATE1 and hOCT2/hMATE1. Biochem Pharmacol. 2008;76:894-903

10. Bachmakov I, Glaeser H, Fromm MF, Konig J. Interaction of oral antidiabetic drugs with hepatic uptake transporters: focus on organic anion transporting polypeptides and organic cation transporter 1. Diabetes. 2008;57:1463-9.

11. Creight MLJ, Bailey CJ, Pearson ER. Metformin and the gastrointestinal tract. Diabetologia. 2016;59(3):426-35.

12. Todd JN, Florez JC. An update on the pharmacogenomics of metformin: progress, problems and potential. Pharmacogenomics. 2014;15(4):52939.

13. Yoon H, Cho HY, Yoo HD, Kim SM, Lee YB. Influences of organic cation transporter polymorphisms on the population pharmacokinetics of metformin in healthy subjects. AAPS J. 2013;15(2):571-80.
14. Ronaghi M, Uhlen M, Nyren P. A sequencing method based on real-time pyrophosphate. Science. 1998;281:363-5.

15. Sanger F, Nicklen S, Coulson AR. DNA sequencing with chain-terminating inhibitors. Proc Natl Acad Sci USA. 1977;74:5463-7.

16. Becker ML, Visser LE, Schaik VRH, Hofman A, Uitterlinden AG, Stricker BH. Interaction between polymorphisms in the OCT1 and MATE1 transporter and metformin response. Pharmacogenet Genomics. 2010;20(1):38-44.

17. Xiao D, Guo Y, Li X, Yin JY, Zheng W, Qiu XW, et al. The Impacts of SLC22A1 rs594709 and SLC47A 1rs2289669 Polymorphisms on Metformin Therapeutic Efficacy in Chinese Type 2 Diabetes Patients. Int J Endocrinol. 2016;2016:4350712.

18. Vilvanathan S, Gurusamy U, Mukta V, Das A, Chandrasekaran A. Allele and genotype frequency of a genetic variant in ataxia telangiectasia mutated gene affecting glycemic response to metformin in South Indian population. Indian $\mathrm{J}$ Endocrinology Metabolism. 2014;18(6):850.

19. Islam T, Rahman MS, Paul N, Akhteruzzaman S, Sajib AA. Allele-Specific Detection of SLC22A2 rs316019 Variants Associated with Metformin Disposition through the Kidney. Int $\mathrm{J}$ Diabetes Metabolism. 2018:22-8.

20. Umamaheswaran G, Arunkumar A, Shewade D, Praveen R, Das A, Adithan C. Genetic analysis of OCT1 gene polymorphisms in an Indian population. Indian J Human Genetics. 2011;17(3):164.

Cite this article as: Phate SD, Daswani BR, Mishra DN, Joshi KS. Genetic analysis of SLC47A1, SLC22A1, SLC22A2, ATM gene polymorphisms among diabetics in an Indian population. Int $\mathrm{J}$ Basic Clin Pharmacol 2020;9:891-6. 